\title{
PREOPERATIVE PREDICTION OF DIFFICULT LAPAROSCOPIC CHOLECYSTECTOMY: IN ZAGAZIG UNIVERSITY HOSPITALS
}

By

Yasser Baz Ghanem, Khalid Safwat Fahmy, Doaa Omar Refaat, Moustafa Baiomy mouhammed General surgery department, faculty of medicine, Zagazig University

Corresponding author:

Yasser Baz Ghanem

Tel. No.:+201095724123
Background: Laparoscopic Cholecystectomy (LC) becomes the standard of care for patients requiring removal of gallbladder. LC may be rendered difficult by various problems encountered during procedure. Several factors have been implicated with a difficult case, but no reliable criteria are available yet to identify patients preoperatively with a difficult LC. Preoperative prediction of a difficult LC can help the patient as well as the surgeon prepare better for the intraoperative challenges and tailored approach accordingly. The present study was undertaken to determine the association between preoperative clinical, laboratory and abdominal sonographic findings in patients undergoing LC for cholelithiasis and the technical difficulty at operation and to predict the most important indicators that affect the operation outcome in order to make the procedure safer for the patient as well as the surgeon.

Methods: In 300 consecutive patients who underwent LC during 2014 to 2016 patient's characteristics, clinical history, laboratory data, ultrasonography results and intraoperative details were prospectively analyzed to evaluate predictors of difficult LC.

Results: Gender, age, obesity, history of hospitalization for acute cholecystitis, history of previous ERCP, history of previous abdominal surgery, Gall bladder size, GB wall thickening, pericholecystic fluid collection, large multiple GB stones and liver US findings; The above mentioned factors were found to have a statistical significant association with the final operation out come.

Conclusions: Obesity, presence of history of previous abdominal surgery, gall bladder wall thickness and gallbladder stone size by preoperative ultrasound; were found to be the predictive factors of difficult LC in our study.

Keywords: Preoperative, Difficult, Laparoscopic cholecystectomy, Prediction.

\section{INTRODUCTION}

G allstone disease (GSD) is one of the most common problems affecting the digestive tract. ${ }^{(1)}$ Cholecystectomy is probably the most commonly performed operation by the surgeons worldwide. (2) Revolution in the treatment of gallstones came in 1987 when first LC was performed. Since then there was no turning back and LC became an established procedure. (3)

The advantages of laparoscopic surgery over the traditional surgery include minimal postoperative pain, shorter hospital stay, a cosmetically better outcome, and earlier recovery ${ }^{(4)}$. Although LC is safe, effective and commonly performed operation, it has some difficulties in the different stages of the operation (5). The difficult gallbladder is the most common 'difficult' laparoscopic surgery being performed by general surgeons all over the world. $^{(\mathbf{1})}$ Because LC is extensively practiced worldwide, the total number of patients suffering severe complications is considerably high despite its low incidence rate, making it a "rare but common" problem. To decrease these complications, various attempts have been made to clarify predictive factors ${ }^{(6)}$.

Pre-operative prediction of "difficult LC" may not only improve patient safety but also be useful in reducing the overall cost of therapy and it may help a surgeon in deciding the approach (open /laparoscopic) most suitable for a particular patient, counselling the patient about it, thereby reducing the morbidity, 
complication, rate of conversion and overall cost of therapy. ${ }^{(7)}$

Factors affecting the outcomes of LC have been heavily investigated over the past years. ${ }^{(8)}$ Presently there is no scoring system available to predict difficulty and the degree of difficulty. (9) There are various pre or peroperative factors that make LC a technically difficult procedure. These include acute cholecystitis, empyema gall bladder, gangrenous cholecystitis, fibrosed gallbladder, severe adhesions in calot's triangle and intrahepatic gall bladder. These problems are difficult to assess preoperatively but are usually encountered during LC and therefore responsible for major difficulty in performing the surgery. ${ }^{(3)}$

The aim of this study is to determine the association between preoperative clinical, laboratory and abdominal sonographic findings in patients undergoing laparoscopic cholecystectomy for cholelithiasis and the technical difficulty at operation and to predict the most important indicators that affect the operation outcome.

\section{MATERIAL AND METHODS}

This study was conducted from May 2014 to September 2016 in the Department of general Surgery, Zagazig University Hospitals. A total of 300 patients with symptomatic GSD who were admitted for cholecystectomy and all subjected to LC were included in this study . The admission sheet is used to collect data about: the Patients' characteristics (Gender, Age, Weight and height for Body mass index calculation) and detailed history about abdominal pain or pain in right hypochondrium, lump in right hypochondrium, vomiting, dyspepsia and fever. Detailed Clinical examination of the patient was done. Site of right hypochondrium was especially examined for assessment of murphy's sign, palpable mass, and visceromegaly. Systemic review was also done to see any comorbidity. For all patients: complete blood count, liver function test, kidney function test, Coagulation profile, random blood sugar alkaline phosphatase and GGT were done . Ultrasonography was performed for all patients following standardized protocol with assessment of gallbladder Shape and Size, Pericholycystic collection, Gallbladder wall thickness, the calculus size, the number of calculi, Common bile duct (diameter and stones) and Liver parenchyma.

Preoperatively Informed consent regarding the procedure was taken. Prophylactic antibiotics were given intravenously in a single preoperative dose within one hour of skin incision and re-dosed when the procedure is more than 4 hours long, NPO for at least 6 hours, Shower and cleaning abdomen and groin area with mild antibacterial soap, Deep Venous Thrombosis Prophylaxis in patients with two or more risk factors.

Surgical procedure of LC was performed on the standard 4-ports technique, Post operatively the nasogastric tube was removed at the end of operation, the drain, if inserted, was removed in the following day if there is no bile in it and minimal blood loss has occurred and Majority of patients were discharged on the following day .

Evaluation of surgical difficulty was according to Iwashita et al. 2016; ${ }^{(6)}$ as they had generated a list of important objective findings that potentially correlate with surgical difficulty during LC. A total of 30 items were categorized into three groups. grading of each item on a seven-stage scale ranging from 0 (easiest) to 6 (most difficult) by a total of 61 expert LC surgeons in Japan, Korea, and Taiwan who participated in the survey. The left and right ends of the whiskers represent the minimum and maximum of all the responses, respectively. The width of each box indicates the interquartile range (IQR), which consists of the middle $50 \%$ of the data.

Table1: seven stage scale of surgical difficulty (6)

\begin{tabular}{|l|l|l|l|l|l|l|}
\hline $\mathbf{0}$ & $\mathbf{1}$ & $\mathbf{2}$ & $\mathbf{3}$ & $\mathbf{4}$ & $\mathbf{5}$ & $\mathbf{6}$ \\
\hline $\begin{array}{l}\text { Easiest } \\
\text { difficult }\end{array}$ \\
\multicolumn{6}{|c|}{$\mathbf{0 1 2 3 4 5 6}$} & $\rightarrow$ Most \\
\hline
\end{tabular}
analysis we used a two likert scale instead of 
seven stage scale; 0 and 1 stage for easy LC and 2, 3, 4, 5 and 6 stages for difficult LC.

Table 2: two stage scale of surgical Difficulty

\begin{tabular}{|l|l|l|l|l|l|l|}
\hline 0 & 1 & 2 & 3 & 4 & 5 & 6 \\
\hline $\begin{array}{l}\text { Easy } \\
\text { LC }\end{array}$ & \multicolumn{5}{|c|}{ Difficult LC } \\
\hline
\end{tabular}

\section{STATISTICAL ANALYSIS}

After data collection for all patients (Patients' characteristics, clinical data included, laboratory data included, ultrasonographic data and operative parameters) data were code22d, entered and analyzed using SPSS (Statistical Package for Social Science) version 19. Chisquare and fisher exact test were used for comparing descriptive data (table 1) and student t test and Mann-Whitney U Test were used for comparing quantitative data (table 2 and 3 respectively). $\mathrm{P}$ value $(\leq 0.05)$ was considered significant difference. Subsequently, those variables of statistically significant associations $(\mathrm{P}$ value $<.05)$ in the univariate analyses were entered into a logistic regression model (table 6). A logistic regression was performed to ascertain the effects of independent variables on the likelihood that patient have difficult operation.

\section{RESULTS}

It was found that patients with thick GB wall, pericholecystic fluid collection, large multiple GB stones, hepatomegaly and/or cirrhotic liverUS findings have more difficulties during LC (table 3, 4and 5), on contrary; there were no statistical significant associations between duration of symptoms of cholecystitis, Clinically palpable GB, history of diabetes, history of jaundice, WBC, liver enzymes, bilirubin level, ALP, GGT, CBD, sonographic condition and conversion to open cholecystectomy and the difficulty of laparoscopic cholecystectomy. Logistic regression was done to the significant factors affecting the difficulty of operation and it was found that large stone size, thick gall bladder wall, high BMI and presence of history of previous surgery were the predictive factors of difficult LC (table 6).

\section{DISCUSSION}

Although LC is safe, effective and commonly performed operation, it has some difficulties in the different stages of the operation. ${ }^{(5)}$ The preoperative prediction of a "difficult" procedure can be very important in this setting and can help the surgeon in being better prepared for the intra-operative challenges to give a tailored approach to older patients. ${ }^{(10)}$ There is a need to evaluate various factors responsible for difficult laparoscopic cholecystectomy. ${ }^{(11)}$

The patient gender was found to be a highly significant factor that associate the difficulty of LC $(p=0.001)$. Alqahtani et al. in 2015 found that male gender as an isolated risk factor has an impact on the outcomes of LC as gender affects the conversion rate and duration of surgery because more time is required to complete LC in men than in women. Rothman et al in 2016, found a higher conversion rate in men and it was hard for them to explain that. In contrary; Bhar et al., in 2013 published a 
Table-3: Relation between different variables and operation outcome

\begin{tabular}{|c|c|c|c|c|c|c|}
\hline \multirow[t]{2}{*}{ Predictable Factors } & & \multicolumn{3}{|c|}{ Final operation outcome } & \multirow[t]{2}{*}{ Test } & \multirow[t]{2}{*}{ P value } \\
\hline & & Difficult & Easy & Total & & \\
\hline \multirow[t]{2}{*}{ Gender } & Female & 117 & 127 & 244 & \multirow[t]{2}{*}{ Chi-square test } & \multirow[t]{2}{*}{0.001} \\
\hline & Male & 41 & 15 & 56 & & \\
\hline \multirow[t]{2}{*}{ History of hospitalization for acute cholecystitis } & No & 138 & 138 & 276 & \multirow[b]{2}{*}{ Chi-square test } & \multirow[t]{2}{*}{0.002} \\
\hline & Yes & 20 & 4 & 24 & & \\
\hline \multirow[t]{2}{*}{ History of ERCP } & No & 141 & 139 & 280 & \multirow[t]{2}{*}{ Chi-square test } & \multirow[t]{2}{*}{0.001} \\
\hline & Yes & 17 & 3 & 20 & & \\
\hline \multirow[t]{2}{*}{ Clinically Palpable GB } & No & 156 & 142 & 289 & \multirow[b]{2}{*}{ Fisher exact test } & \multirow[b]{2}{*}{0.5} \\
\hline & Yes & 2 & 0 & 2 & & \\
\hline \multirow[t]{2}{*}{ History of D.M } & No & 145 & 128 & 273 & \multirow[b]{2}{*}{ Chi-square test } & \multirow[b]{2}{*}{0.6} \\
\hline & Yes & 13 & 14 & 27 & & \\
\hline \multirow[t]{2}{*}{ History of jaundice } & No & 145 & 133 & 278 & \multirow[b]{2}{*}{ Chi-square test } & \multirow[b]{2}{*}{0.5} \\
\hline & Yes & 13 & 9 & 22 & & \\
\hline \multirow[t]{4}{*}{ History of previous surgery } & No & 111 & 92 & 203 & & \\
\hline & Lower & 36 & 44 & 80 & & \\
\hline & Upper & 2 & 5 & 7 & Chi-squre test & 0.02 \\
\hline & Both & 9 & 1 & 10 & & \\
\hline Liver enzymes levels & Normal & 146 & 129 & 275 & & \\
\hline & Elevated & 12 & 13 & 25 & Chi-squre test & 0.6 \\
\hline Bilirubin level & Normal & 149 & 134 & 283 & Chi-squre test & 0.98 \\
\hline & Elevated & 9 & 8 & 17 & & \\
\hline Alkaline phosphatase level & Normal & 150 & 130 & 280 & Chi-squre test & 0.24 \\
\hline & Elevated & 9 & 11 & 20 & & \\
\hline GGT level & Normal & 145 & 133 & 278 & Chi-squre test & 0.5 \\
\hline & Elevated & 13 & 9 & 22 & & \\
\hline GB shape and size & Distended & 43 & 18 & 61 & Chi-squre test & 0.01 \\
\hline & Normal & 115 & 124 & 239 & & \\
\hline Pericholecystic fluid collection & No & 148 & 141 & 289 & Chi-square test & 0.01 \\
\hline & Yes & 10 & 1 & 11 & & \\
\hline GB wall thickness & Normal & 69 & 107 & 167 & Chi-squre test & $<0.001$ \\
\hline & Thick & 89 & 35 & 124 & & \\
\hline GB stone size & Small & 76 & 95 & 171 & Chisqure test & 0.001 \\
\hline & Large & 82 & 47 & 129 & & \\
\hline GB stones number & Multiple & 121 & 122 & 242 & Chi-squre test & 0.004 \\
\hline & Solitary & 37 & 20 & 57 & & \\
\hline CBD condition & Average & 152 & 140 & 292 & Fisher exact test & 0.5 \\
\hline & Dilated & 4 & 2 & 6 & & \\
\hline & Have stone & 2 & 0 & 2 & & \\
\hline Liver ultrasonographic condition & Average & 99 & 101 & 200 & Fisher exact test & 0.02 \\
\hline & Fatty & 39 & 36 & 75 & & \\
\hline & Enlarged & 17 & 5 & 22 & & \\
\hline & Cirrhotic & 3 & 0 & 3 & & \\
\hline Conversion to open cholecystectomy & No & 156 & 142 & 298 & Chi-squre test & 0.18 \\
\hline & Yes & 2 & 0 & 2 & & \\
\hline
\end{tabular}

Table-4: Relation between (age, BMI, Duration of operation) and operation outcome

\begin{tabular}{|l|l|l|l|l|}
\hline & Difficult & Easy & T test & P value \\
\hline Age & $45.7 \pm 13.0$ & $37.2 \pm 12.1$ & 5.84 & $0.0001 * \mathrm{~S}$ \\
\hline BMI & $35.0 \pm 7.3$ & $30.4 \pm 6.2$ & 5.85 & $0.0001 * \mathrm{~S}$ \\
\hline Duration of operation & $108.69 \pm 32$ & $45.8 \pm 13.1$ & 21.8 & $0.0001 * \mathrm{~S}$ \\
\hline
\end{tabular}


Table-5: Relation between (duration of symptoms and TLCs) and operation outcome

\begin{tabular}{lccccc}
\hline & & Median for DLC & Median for ELC & Mann- Whitney U & P value \\
\hline Duration of symptoms & & 2.0 & 1.0 & 10063 & 0.12 \\
\hline Total leucocytic count & $\left(\times 10^{3}\right)$ & 7.7 & 7.2 & 10192.5 & 0.175
\end{tabular}

Table (6) Logistic regression to ascertain the effects of independent variables(predictors) on operation outcome

\begin{tabular}{lrrrrr}
\hline \multicolumn{1}{c}{ VARIABLES } & B & \multicolumn{1}{c}{ S.E } & \multicolumn{1}{c}{ Wald } & \multicolumn{1}{c}{ P value } & \multicolumn{1}{c}{ OR } \\
\hline Gender & -1.832 & 1.029 & 3.169 & 0.075 & 0.160 \\
\hline Age & -0.048 & 0.033 & 2.119 & 0.145 & 0.953 \\
\hline BMI & -0.174 & 0.069 & 6.330 & $\mathbf{0 . 0 1 2}$ & 0.840 \\
\hline Previous hospitalization & 1.593 & 2.248 & 0.502 & 0.478 & 4.921 \\
\hline Duration of symptoms & -0.146 & 0.251 & 0.340 & 0.560 & 0.864 \\
\hline History of ERCP & 0.577 & 1.703 & 0.115 & 0.735 & 1.781 \\
\hline History of previous surgery & 4.133 & 2.066 & 4.002 & $\mathbf{0 . 0 4 5}$ & 62.374 \\
\hline Gall bladder shape & 1.629 & 0.973 & 2.804 & 0.094 & 5.101 \\
\hline Pericholecystic collection & -2.085 & 11.510 & 0.033 & 0.856 & 0.124 \\
\hline Gall bladder wall thickness & 3.536 & 1.156 & 9.346 & $\mathbf{0 . 0 0 2}$ & 34.312 \\
\hline Gall bladder Stone size & 3.899 & 0.985 & 15.670 & $\mathbf{0 . 0 0 0}$ & 49.348 \\
\hline Gall bladder Stone numbers & -0.481 & 0.855 & 0.317 & 0.574 & 0.618 \\
\hline Operation duration & -0.207 & 0.038 & 29.780 & $\mathbf{0 . 0 0 0}$ & 0.813
\end{tabular}

study suggesting that male sex was not statistically significant predictor of difficult LC (p 1.00). This finding was in conformity with that of Nityasha, et al in 2016. Chandrashekhar and Kailas in 2017 published that gender had little influence on the course of surgery which may be due to small size of their sample.

The patients age was found to be a highly significant factor for associating difficulty of LC; a mean of $45.7 \pm 13.0$ years was found in the patients associated with difficulty while mean of $37.2 \pm 12.1$ years in easy cases ( $\mathrm{P}$ value $=0.0001)$. many researchers have found age $>60$ years as predictor of difficult LC and the reason for older age being at risk is due to a longer history of gallstones and increased number of acute attacks of cholecystitis. Besides, elderly patients have a higher likelihood of complicated biliary pathology as puplished by Kidwai et al. in 2016. In conformity; Agarwal et al. in 2016 published a study suggesting elderly patients were more prone to have a difficult LC, also Chong et al. in 2016 found that LC in elderly patients is associated with higher complications rates and longer hospital stays. However Sandhu and Rana in 2016 published that there was no significant association was found between age and outcome of LC and that was in conformity with Chandrashekhar and Kailas study in 2017 found that age was not a significant $(\mathrm{p}=1.59)$ factor for predicting difficulty in LC.

Obesity was found to be a significant associative factor of difficulty in LC ( $\mathrm{P}$ value $=0.0001)$ in conformity with Chandrashekhar and Kailas (2017) study which demonstrated that the mean BMI was $24 \mathrm{~kg} / \mathrm{m} 2$ and 4 of patients were considered obese and all 4 cases were difficult ( $\mathrm{p}=<0.000)$. Lowndes et al. (2016) had claimed the obesity for the risk factor of difficult laparoscopic cholecystectomy. However; Solmaz et al. (2016) in their study as they found some opposite data. Nityasha et al (2016) found that 
obesity was not significant $(\mathrm{p}=0.390)$ in prediction of difficulties in laparoscopic cholecystectomy. Ahmed et al. (2014) found that obesity was a significant predictive factor for predicting difficulity in access to peritoneal cavity $(\mathrm{p}=0.0133)$. Inconformity Ranga and Arora (2016) cocluded that obese patient was found to be as one conditions predicted to had difficult LC.

History of hospitalization of recurrent attacks of acute cholecystits iwas found to be a significant factor for prediction of difficult LC $(p=0.002)$ although duration of symptoms was not found to be a significant factor for predicting difficulty $(\mathrm{P}$ value $=0.12)$. Ahmed et al. (2014) found that history of acute attacks was a significant predictive factor for predicting difficulty in predicting dense adhesions at calot's triangle $(\mathrm{p}=0.032)$. Nidoni et al. (2015) their study data analysis revealed that there was significantly high risk of difficulty and conversion in patients with previous history of more than 2 attacks of acute cholecystitis $(\mathrm{p}=0.03,95 \%$ confidence interval). Bourgouin et al. (2016) previous cholecystitis attacks strong predictive factor of difficult LC ( $p=$ $<0.001$ ). Nityasha et al. (2016) History of acute cholecystitis was found to be highly significant predictor of difficulty in laparoscopic cholecystectomy $(p<0.021)$ and patients with such past history were found to have 5.3 times more risk of having a difficult operation. Agarwal et al. (2016) concluded that Longer duration of symptoms have high chance of difficult LC due to recurrent cholecystitis. Chandrashekhar and Kailas in 2017 found that one of the preoperative parameters that significantly predicted difficult LC based on the clinical criterion of was presence of previous hospitalization for acute cholecystitis $(\mathrm{p}=<0.005)$.

The studies from early 1990s found significant association of conversion with previous endoscopic retrograde cholangio pancreatography (ERCP) as published by Mok et al.(2016) as they were decided that ERCP rather than CBD stones would be included as a covariate in the logistic regression models for predicting difficult dissection and conversion to open surgery $(\mathrm{p}=<0.001)$ though Aktimur et al. (2015)found that preoperative ERCP was not significant cause of conversion $(p=0.999)$ but Solmaz et al. 2016 in a study evaluation of the parameters increasing intra operative difficulty scores of elective laparoscopic cholecystectomy found that ERCP was a significant predictive factor for LC. In our series it was found to be a significant factor for prediction of difficulty as history was positive in 20 patients $(6.7 \%)$ and 17 patients of them $(85 \%)$ had difficulty during operation.

History of jaundice was not found to had any predictive significance for difficult access to peritoneal cavity, dense adhesions at calot's triangle, dissection of the gall bladder bed or difficult extraction $(\mathrm{p}=0.236,0.521,0.41$, 0.652 respectively) as published by Ahmed et al. in 2014 but Abdulhussein et al. (2015) found that history of jaundice was significant predictive factor $(\mathrm{p}=<0.001)$ associated with conversion to open cholecystectomy. In our series it was not significant predictive factor for LC as we found that 22 patients had history of jaundice; 13 patients of them had difficulties others 9 patient had easy LC $(\mathrm{P}=0.5)$.

History of Diabetes Mellieutes (DM) was found to be a significant predictive factor for difficulties during LC in a published study of Bhar et al. (2013) they claimed diabetes had positive correlation with difficulties encountered in LC (p 0.025) as In diabetic patients there may be several attacks of sub acute inflammation causing more scarring and making cholecystectomy more difficult. Conformity Sanniyasi et al. (2016) found that diabetes is a statistically significant predictor $(\mathrm{p}$ $<0.05)$ of difficult laparoscopic cholecystectomy. Chong et al. (2016) published D.M was predictive factor for lengthened postoperative stay. On the other hand Rothman et al. (2016) published none of the 6 studies evaluating diabetes mellitus as a risk factor found it to be significant. Lowndes et al. (2016) despite its inclusion in other available predictive models diabetes was not statistically significant in this regression model as 
predictors of prolonged operative duration. In conformity in our seris it was found to be non significant $(\mathrm{P}=0.6)$ factor in preoperative prediction of difficult LC.

History of previous abdominal surgery was found to be a significant predictive factor for difficulty during LC ( $\mathrm{p}=0.02)$ in our study. Bhar et al. (2013) they did not find any significant correlation ( $p$ 0.115) between past abdominal surgeries and difficulties encountered during LC which is in accordance with the study of Kumar et al. (2015) as they were published that previous surgery was not significant $(\mathrm{p}=0.88)$ predictive risk factor for difficult LC. Sandhu and Rana (2016) found that the abdominal scar in has not been a significant association $(\mathrm{p}=1.000)$ with the outcome of LC. Ko-iam et al. (2017) found that it was non significant $(\mathrm{p}=0.716)$ Predictive Factors for a long hospital stay in patients undergoing LC. Singh and Nath (2016) found that Previous abdominal scar (supraumbilical) will lead to conversion to open cholecystectomy in conformity Agrawal et al., (2016) published that upper abdominal scars was found to be statistically significant factor.

In our study two patients only had clinically palpable gallbladder and both of them had difficulty during operation while 156 patients of 298 non palpable gallbladder patients had also difficulties during their LC so it was not a significant factor $(p=0.5)$ for predicting difficulty. Sugrue et al. (2015) published palpable gallbladder has been shown to increase the likelihood of a difficult procedure and in conformity Kumar et al. (2015) found it to be significant clinical predictive factor $(\mathrm{p}=0.021)$ in LC. Agrawal et al., (2016) clinically palpable GB was found to be predictor of difficult LC. Singh and Nath (2016) published If gall bladder is palpable then it would be difficult, as there may be residual inflammation adhesion. Elhady and Esmail (2017) found that presence of palpable tender right hypochondrial mass was risk factor for difficulty, complications, operative and postoperative outcome in patients undergoing LC for acute cholecystitis.
Total Leucocytic Count (TLC) was found to had no significant statistical association with difficulty of LC $(p=0.175)$ with median TLC 7700 for easy LC and 7200 for difficult cases. Lowndes et al. (2016) found that WBC was non significant risk factor of difficult LC. Elhady and Esmail (2017) published high TLC was one of the risk factors for difficulty, complications, operative and postoperative outcome in patients undergoing LC for AC in contrary;. Hosseini et al. (2014) found that it was significant factor for evaluation of postoperative complication of LC in diabetic patients $(\mathrm{p}=0.055)$. Kumar et al. (2015) and Nidoni et al. (2015) published that TLC > 11000 was significant predictive factor $(p=0.0239)$ for difficult LC and for conversion $(p=0.037)$ respectively. Mok et al.(2016) found in their study that WBC; was 7750 for easy LC, 9500 for difficult LC $(p=0.002)$ and 12350 for conversion to open $(p<0.001)$. Sanniyasi et al. (2016) found that Mean TC for easy LC was 8769 and was 10680 for difficult $\mathrm{LC}(\mathrm{p}=0.001)$.

we found that liver enzymes (AST and ALT) levels were abnormal in 25 patients 13 patients of them had a difficult LC and it was not significant factor for predicting DLC ( $p$ $=0.6$ ). Bat (2015) found that AST, ALT, ALP, GGT and total bilirubin all of them were non significant factor for conversion to open surgery $(\mathrm{P}=0.3,0.6,0.9,0.9,0.1$ and 0.4 respectively). In conformity; Kaneko et al. (2015) AST, ALT and total bilirubin all non significant Predictors of prolonged LC in the treatment of low-grade acute cholecystitis. In contrary; Agarwal et al. (2016) In their study they found that patients found to be difficult or converted to open had high side of LFT in conformity; Lowndes et al. (2016) had claimed the abnormal LFT for the risk factor of difficult LC but Terho et al. (2016) found that ALAT, ALP and bilirubin all non significant ( $\mathrm{p}=0.214$, 0.075 and 0.668 respectively.

Serum Bilirubin, alkaline phosphatase (ALP) and gamma glutamyle transferase (GGT) were found abnormally elevated in 17, 20 and 22 patients respectively and it was found that all of them had no significant statistical 
association with the operation out come during LC $(\mathrm{P}=0.98, \quad 0.24$ and 0.5 respectively). Sanniyasi et al. (2016) found that Mean bilirubin for easy and difficult LC was 1.77 and 1.22 respectively $(\mathrm{p}=0.182)$. Domínguez et al (2011) published; Total bilirubin $>2 \mathrm{mg} / \mathrm{l}$ was Significant ( $\mathrm{p}<0.04$ ). Bourgouin et al. (2016) puplished that ALP was a significant predictive factor LC ( $\mathrm{p}$ value $<0.001$ ) in high levels 80159 and $\geq 160 \mathrm{IU} / \mathrm{L}$. while GGT was significant in $\geq 150$ IU/L levels only with $p$ value $<0.001$ and 0.060 for 50- 149 IU/L. Sanniyasi et al. (2016) found that Mean ALP for easy LC was 112 and was 115 for difficult LC with $p$ value 0.749 .

Gallbladder wall thickness on sonography was found to had a high significant statistical association with the final outcome of LC $(p<0.0001)$ in our study. Rizvi et al. (2012) claimed the most valuable assessment that ultrasound can provide is gallbladder wall thickness. Kala et al. (2014) published that GB wall thickness >4 mm was considered as predictors of difficult LC and the same has been shown in the various literatures as that of Singh and Nath (2016) and Sandhu and Rana (2016). Kumar et al (2015) published palpable thick walled Gall bladder on USG was a significant factor for difficult LC ( $p$ 0.036). Zaman et al. (2015) found that Chances of conversion however, increased with increasing thickness of the gall bladder. Agrawal et al. (2016) Increased GB wall thickness is associated with difficult dissection of the GB from its bed. Nityasha et al. (2016) found in their study, thickened gall bladder wall was found to be a significant predictor of difficulty $(\mathrm{p}<0.001)$ and was significantly associated with adhesions $(\mathrm{p}<0.002)$, bleeding $(\mathrm{p}<0.0001)$, increased operating time $(\mathrm{p}<0.0001)$ and All the three converted patients had thickened gall bladder wall. Chandrashekhar and Kailas (2017) published Significantly intraoperative difficulty $(\mathrm{P}<0.000)$ was demonstrated in patients with GB wall thickness greater than $3 \mathrm{~mm}$ that may be due to difficulty during grasping the gall bladder, difficult GB bed dissection and higher incidence of bleeding. Kania (2017) recommended that it should be borne in mind that ultrasound assessment of the gall-bladder wall, even if no pathology has been found, remains an auxiliary examination and does not mean that the operator should not be watchful and thoughtful while skeletonising the Calot's triangle structures.

There was a statistical significant association between Pericholecystic collection on Sonography and LC difficulty in our study $(p<0.01)$. Kumar et al. (2015) published that evidence of Pericholecystic collection on Sonography was associated with difficult LC. Nidoni et al. (2015) found that patients with pericystic collection had significant high rates of difficulty and conversion compared to patients without collection. Agrawal et al. (2016) Pericholecystic collection was found to be a strong predictor of difficult LC. Sandhu and Rana (2016) found to have stastically significant association ( $p$ value 0.004 ) with difficult LC. Chandrashekhar and Kailas (2017) found that Pericholecystic collection was not statistically significant in predicting difficulty $(\mathrm{P}=1.18)$.

Bat (2015) found that gallbladder stone number was not significant $(\mathrm{p}=0.5)$. Kidwai et al (2016) found that Patients with multiple GB calculi had difficulty during LC. Husain et al (2016) found that multiple stones were a non significant factor for difficult and very difficult LC ( $p$ > 0.05). In our series; we found that it was a significant predictive factor for difficult LC ( $\mathrm{p}<0.004)$. Ahmed et al. (2014) found that large stone was a significant predictive factor for predicting difficulty in extraction $(\mathrm{p}=$ 0.022) but not significant for access to peritoneal cavity, dense adhesions at calot's triangle and dissection of gallbladder from it 's bed ( $\mathrm{p}=0.23,0.32,0.336$ respectively). Bat (2015) found that stone size was not significant $(\mathrm{p}=0.4)$ in Comparison of patients operated successfully with LC and converted to open surgery. Gupta et al. (2015) in their study difficulty in GB extraction was associated with size of GB stone $>15 \mathrm{~mm}$. Kidwai et al. (2016) cocluded that Impacted stones at Hartmann's pouch makes dissection difficult because of 
difficulty in holding GB at Hartmann's pouch. Husain et al (2016) found that stone size more than $1 \mathrm{~cm}$ was a significant factor for difficult and very difficult $\mathrm{LC}$ with $(\mathrm{p}<0.05)$. In our series; we found that it was a significant predictive factor for difficult LC $(\mathrm{p}<0.001)$.

Nityasha et al. (2016) published gall bladder transverse diameter was found to be significant of laparoscopic cholecystectomy $(p=0.0060)$. In our series; we found that it was a significant predictive factor for difficult LC $(\mathrm{p}=0.01)$.

Rosen et al. (2002) found that Stones in CBD on ultrasound $6.4 \%$ for conversion and was $4.0 \%$ for control $(p=0.5560)$. In our series; we found that was a non significant predictive factor for difficult $\mathrm{LC}(\mathrm{p}<0.5)$.

Elsebae et al., 2006 found that hepatomegaly and/or liver cirrhosis were found to be significant predictors of difficulty at LC. Kala et al. (2014) published that as one of many preoperative conditions; advanced cirrhosis was considered as predictors of difficult LC. Husain et al (2016) found that fibrosis of liver parenchyma was a significant factor for difficult and very difficult LC $(\mathrm{p}<0.05)$. In our series; we found that liver ultrasonographic condition was a significant predictive factor for difficult LC ( $p=0.02)$.

The duration of operation was found to be significant factor for predicting difficulty in our study ; a mean of 108.69 32 minutes was found in the patients associated with difficulty while mean of $45.8 \pm 13.1$ minutes in easy cases $(\mathrm{P}$ value $=0.0001)$ and it was found to be one of predictors (independent variables) of difficulty of LC in logistic regression analysis $(\mathrm{p}=<0.001)$ of and this in confirmity with Ko-iam et al. (2017) found that operative duration $>60$ min was a significant predictive factor for a long hospital stay in patients undergoing LC ( $\mathrm{p}=0.011)$.

In the present study Logistic regression was done to the significant factors affecting the difficulty LC and it was found that obesity, history of previous abdominal surgery, gall bladder wall thickness and gallbladder stone size by sonographic imaging; were the predictive factors (independent variables) of difficult LC (table 6) with $\mathrm{p}$ value of 0.012 , $0.045,0.002$ and $<0.001$ respectively their odds ratio were $0.840,62.374,34.312$ and 49.348 respectively. In conformity; Singh and Nath, (2016) found that Previous abdominal scar will lead to difficulty. Sonographically increased GB wall thickness would have more chance of difficult LC, similarly; Gupta et al., 2015 published that the preoperative parameters that significantly predicted difficult LC were ultrasonographic criteria of not only large stones but thick and fibrosed GB due to previous attacks of acute cholecystitis. Kumar et al., (2015) found that the statistically significant factors for predicting difficult LC were $\quad B M I>27.5 \quad(p<0.010)$, previous hospitalization for acute Cholecystitis $(\mathrm{p}<0.001)$, palpable GB $(\mathrm{p}<0.01)$ and Thickened GB wall (USG) ( $\mathrm{p}<.037)$. Bourgouin et al., (2016) published that obesity was not predictive factor for difficult LC as BMI> 34 $\mathrm{Kg} / \mathrm{m}^{2}$ was found to had $\mathrm{p}$ value of 0.093 . Bhar et al. (2013) in their study conclude that diabetes was found to be one of independent statistically significant predictor of difficult LC.

\section{CONCLUSION}

There were statistical significant association between gender, age, obesity, history of hospitalization for acute cholecystitis, history of previous ERCP, history of previous surgery, Gallbladder size, GB wall thickness, pericholecystic fluid collection, GB stone size and number, hepatomegaly and/or cirrhotic liver US findings and surgical difficulty of LC while; Obesity, presence of history of previous abdominal surgery, gall bladder wall thickness and gallbladder stone size by preoperative ultrasound; were found to be the predictive factors of difficult LC in our study.

\section{RECOMMENDATIONS}

Pre-operative US is no doubt good predictor of difficult LC in majority of cases but more attention should be given to demographic data, history and clinical examination to predict the difficult LC. the knowledge of these findings might help in better psychological preparation of the patients for open surgery and prolonged 
convalescence, it will also allow for better organization of the operating room schedule ultimately leading to reduction in procedurerelated costs, should help to avoid an inexperienced laparoscopic surgeon having to operate on a gallbladder which is too difficult for him to perform laparoscopically; depending on the difficulties expected from preoperative evaluation, elect surgeon for the operation, It would decrease the duration of operating procedure and It would help in taking quick decision whether to pursue the procedure laparoscopically or to convert it into open procedure if the risk factors was in our mind before starting the procedure. So keeping an eye to the factors of difficult LC before starting the operation will significantly reduce the post operative morbidity.

\section{REFRANCES}

1. Sandhu G. and Rana M. L.: preoperative prediction of difficult laparoscopic cholecystectomy: A scoring method. Indian Journal of applied research. 2016;6(6):1-6.

2. Chaudhary R., Sharma K., Shukla A., Gupta A., Saurabh K. and Parashar A.: Cystic Duct Opening into Right Hepatic Duct; a Disaster Waiting to Happen During Cholecystectomy: A Case Report. iMedPub Journals Translational Biomedicine 2016; 7(2:59):1-3.

3. Brohi S., Dr., Khan M. L., Shaikh U. and Shaikh S. U.: Laparoscopic cholecystectomy; To assess various intra operative predictive factors which are responsible for difficulty in performing laparoscopic cholecystectomy. Professional Med J 2014; 21(4): 601-605.

4. Sanniyasi S., Rajappa P., Thiyagarajan M. , Reddy A. and Reddy A.: Analysis of predictors of a difficult laparoscopic cholecystectomy. Int Surg J. 2016 Aug; 3(3):1322-1324.

5. Solmaz A, Gülçiçek OB, Biricik A, Erçetin C, Yiğitbaş H, Yavuz E., Çelik A. and Çelebi F.: Evaluation of the Parameters Increasing Intraoperative Difficulty Scores of Elective Laparoscopic Cholecystectomy. J Liver Clin Res. 2016; 3(1):1023-1028.

6. Iwashita Y., Tetsuji O., Goro H., Hibi T., Yoshida M., Miura F., Takada T.: What are the appropriate indicators of surgical difficulty during laparoscopic cholecystectomy? Results from a Japan-Korea-Taiwan multinational survey. J Hepatobiliary Pancreat Sci (2016); 23:533-547.

7. Bhar P., Halder S. K., Ray R. P. and Bhattacharjee: pre-operative prediction of difficult laparoscopic cholecystectomy. Indian Medical Gazette. April 2013; 128-131.

8. Alqahtani_R., Ghnnam W., Alqahtani_M., Qatomah A., AlKhathami_A. and Alhashim A.: Role of male gender in LC outcome. International Journal of Surgery and Medicine (2015); 1(2); 38-42

9. Kumar P., Pankaj A. and Bhushan R.: predicting difficulities in Laparoscopic Cholecystectomy using clinical, laboratory and ultrasonological criteria: A prospective study. $\mathbf{J}$ of Evidence Based Med \& Hlthcare. 26 Oct 2015; 2(43):7667-7672.

10. Guida F., Monaco L., Schettinoi M., Porfidiai R. and Iapicca G.: Predictive factors of difficult procedure in octogenarians undergoing elective laparoscopic cholecystectomy: a single center experience. $\mathrm{G}$ Chir March-April 2016; 37(2): 68-70.

11. Chandrashekhar Naik G. and Kailas C. T.: Predicting difficulty in laparoscopic cholecystectomy by clinical, hematological and radiological evaluation. International Surgery Journal. January 2017; 4(1):1-5.

12. Rothman J.P., Burcharth J., Pommergaard H.C., Viereck S. and Rosenberg J.: Preoperative Risk Factors for Conversion of Laparoscopic Cholecystectomy to Open Surgery - A Systematic Review and MetaAnalysis of Observational Studies. Dig Surg 2016; 33:414-423.

13. Nityasha, Dalal S., Sharma V., Saharan A. and Bakshi V.: Evaluation of predictive factors for conversion of laparoscopic cholecystectomy. International Journal of Enhanced Research in Medicines \& Dental Care. 2016;3:7-10.

14. Kidwai R., Pandit R., Issrani R. and Prabhu N.: Assessment of Risk Factors for Conversion from Difficult Laparoscopic to Open Cholecystectomy - A Hospital Based Prospective Study. Journal of Krishna Institute of Medical Sciences University, JulySeptember 2016; 5(3):84-97.

15. Agarwal D., Arora D., Avasthi A., Kothari A. and Dangayach K.K.: Study of 292 
patients for prediction of difficult laparoscopic cholecystectomy using detailed history, clinical and radiological parameters. International Surgery Journal. Feb 2016; 3(1):349-353.

16. Chong J.U., Lee J.H., Yoon Y.C., Kwon K.H., Cho J.Y., Kim S.J., Kim J.K., Kim S.H., Choi S.B. and Kim K.S.: Influencing factors on postoperative hospital stay after laparoscopic cholecystectomy. Korean J Hepatobiliary Pancreat Surg 2016; 20:12-16.

17. Lowndes B., Thiels C.A., D.O., Habermann E.B., Bingener J., Susan Hallbeck S. and Yu D.: Impact of patient factors on operative duration during laparoscopic cholecystectomy: evaluation from the National Surgical Quality Improvement Program database. The American Journal of Surgery. 2016; 212(I2):289296http://dx.doi.org/10.1016 /j.amjsurg.

18. Ahmed M.L., Lolah M.A., Mohammed M. A., Sharabash M.M.: Difficulties during laparoscopic cholecystectomy. Menoufia Medical Journal 2014; 27:469-473.

19. Ranga H.R. and Arora B.: Difficult Cholecystectomy Strategies in Laparoscopic Cholecystectomy: A Study. Global Journal for Research Analysis. March - 2016 ;5(3):451452.

20. Nidoni R., Udachan T.V., Sasnur P., Baloorkar R., Sindgikar V. and Narasangi B.: Predicting Difficult Laparoscopic Cholecystectomy Based on Clinicoradiological Assessment. Journal of Clinical and Diagnostic Research. Dec 2015;9(12): 9-12.

21. Bourgouin S., Mancini J., Monchal T., Calvary R., Bordes J. and Balandraud P.: How to predict difficult laparoscopic cholecystectomy? Proposal for a simple preoperative scoring system. The American Journal of Surgery. 2016; 212(5):873-881.

22. Mok K.W.J., Goh Y.L., Howell L.E. and Date R.S.: Is C-reactive protein the single most useful predictor of difficult laparoscopic cholecystectomy or its conversion? A pilot study. Journal of Minimal Access Surgery. January-March 2016;12(1):26-32.

23. Aktimur R., Gokakin A.K., Deveci K. and Atabey M.: Conversion to open surgery in the era of laparoscopic cholecystectomy: Changing rates and reasons in geriatric patients. Archives of Clinical Experimental Surgery. 2016; 5:2732.
24. Abdulhussein B. J., Hussein Y. F., Nawar A. H. and Al-Naggar R. A.: Conversion Rate of Laparoscopic Cholecystectomy to Open Surgery at Al Karamah Teaching Hospital, Iraq. Surgical Science, 2015; 6:221-226.

25. Ko-iam W., Sandhu T., Paiboonworachat S., Pongchairerks P., Chotirosniramit A., Chotirosniramit N., Chandacham K., Jirapongcharoenlap $\mathrm{T}$., and Junrungsee S.: Predictive Factors for a Long Hospital Stay in Patients Undergoing Laparoscopic Cholecystectomy. Hindawi Publishing Corporation .International Journal of Hepatology. 2017, Article ID 5497936, 8 pages. https://doi.org/ 10.1155/ 2017/ 5497936.

26. Singh A.K. and Nath U.: Predictor of difficult Laparoscopic Cholecystectomy. Indian Journal of applied research. March 2016; 6(3):619-623.

27. Agrawal N., Singh S. and Khichy S.: Preoperative Prediction of Difficult Laparoscopic Cholecystectomy: A Scoring Method. Nigerian Journal of Surgery. Jul-Dec 2015; 21(2):130-133.

28. Sugrue M., Sahebally S.M., Ansaloni L. and Zielinski M.D.: Grading operative findings at laparoscopic cholecystectomy- a new scoring system. World Journal of Emergency Surgery. 2015; 10:14:1-8. DOI 10.1186/s13017-0150005-x.

29. Elhady H. A. and Esmail T. A. : Is C-reactive Protein an Independent Risk Factor for Complication of Laparoscopic Cholecystectomy for Acute Cholecystitis. Journal of Surgery. 2017; 5(3-1): 16-22.

30. Hosseini S. V. S.: Evaluation postoperative complication of laparoscopic cholecystectomy in diabetic patients. Int. J. Curr. Res. Aca. Rev. 2014; 2(11):107-116.

31. Bat orhan: The analysis of 146 patients with difficult laparoscopic cholecystectomy. Int J Clin Exp Med. 2015; 8(9):16127-16131.

32. Kaneko T., Kuwahara T., Harada T., Kawaoka T., Hiraki S., and Fukuda S.: Predictors of prolonged laparoscopic cholecystectomy in the treatment of low-grade acute cholecystitis: a single-center, retrospective, observational study. Acute Medicine \& Surgery 2015; 2: 190-194.

33. Terho P. M., Leppäniemi A. K. and Mentula P. J.: Laparoscopic cholecystectomy for acute calculous cholecystitis: a retrospective study assessing risk factors for conversion and 
complications. World journal of emergency surgery. 2016.2 Bio Medcentralhttp://creativecommons.org/licenses /by/4.0/.

34. Domínguez L. C., River A., Charles Bermúdez C. and Herreraa W.: Analysis of factors for conversion of laparoscopic to open cholecystectomy: a prospective study of 703 patients with acute cholecystitis. CIR ESP. 2011;89(5):300-306.

35. Rizvi S.A., Ali S.A., Akhtar S., Faridi S. and Ahmad M.: Forecast of difficult Laparoscopic cholecystectomy by Sonography: Biomedical Research. 2012 ; 23(3): 425-429.

36. Kala S., Verma S., and Dutta G.: Difficult Situations in Laparoscopic Cholecystectomy: A Multicentric Retrospective Study. Surg Laparosc Endosc Percutan Tech. 2014; 24(6):484-487.

37. Zaman J., Imaduddin S. and Razzak R.: Frequency of difficult laparoscopic cholecystectomy in patients with thick walled gall bladder. Pak J Surg 2015; 31(3):165-168.

38. Kania Dariusz: Ultrasound measurement of the gallbladder wall thickness in the assessment of the risk of conversion from elective laparoscopic cholecystectomy to open surgery. Polski przeglad chirurgiczny. 2016; 88(6):334-345.

39. Kidwai R., Pandit R., Issrani R. and Prabhu N.: Assessment of Risk Factors for Conversion from Difficult Laparoscopic to Open Cholecystectomy - A Hospital Based Prospective Study. Journal of Krishna Institute of Medical Sciences University, JulySeptember 2016; 5(3):84-97.

40. Husain A., Pathak S. and Firdaus H.: Assessment of Operative Predictors for Difficulty in Laproscopic Cholecystectomy. International Journal of Contemporary Medical Research. 2016; 3(4):1232-1234.

41. Ahmed M.L., Lolah M.A., Mohammed M. A., Sharabash M.M.: Difficulties during laparoscopic cholecystectomy. Menoufia Medical Journal 2014; 27:469-473.

42. Gupta G., Sharma P. V., Gupta S. and Bhardwaj A.: Pre and per operative prediction of difficult laparoscopic cholecystectomy using clinical and ultrasonographic parameters. Int J Res Med Sci. Nov. 2015; 3(11):3342-3346.

43. Rosen M., Brody F. and Ponsky J.: Predictive factors for conversion of laparoscopic cholecystectomy. The American Journal of Surgery 2002;184:254-258.

44. Elsebae M., Saied M., Nasr M., Helmy A. and el Ansari M.: preoperative factors that determine technical difficulty during laparoscopic cholecystectomy for symptomatic calcular cholecystitis. Kasr El Aini Journal of Surgery. 2006; 7 (1):57-6 


\section{التبؤ بصعوبة إستئصال المراره بالتظير الجراحى قبل العمليه بمستثفيات جامعة الزقازيق}

المقدمة

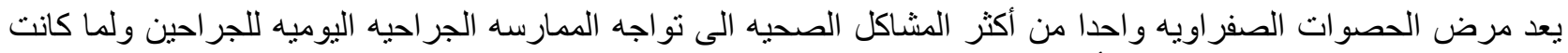

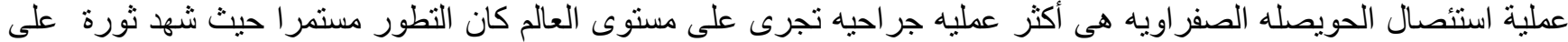

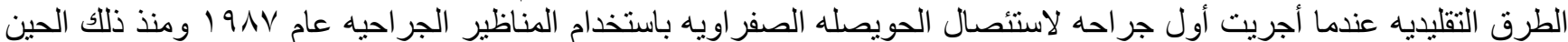

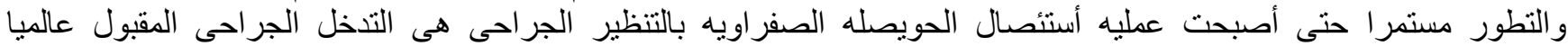

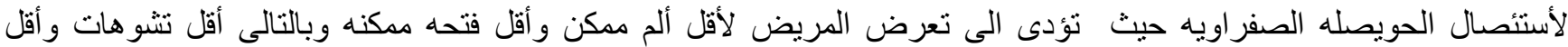

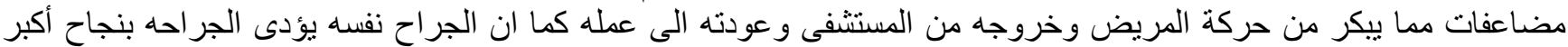

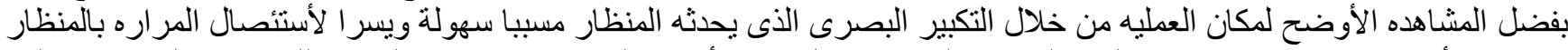

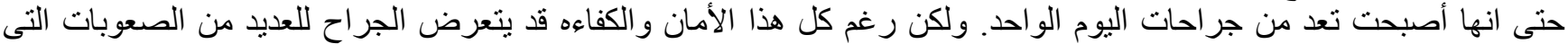

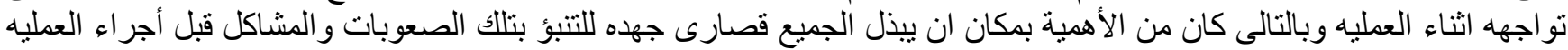

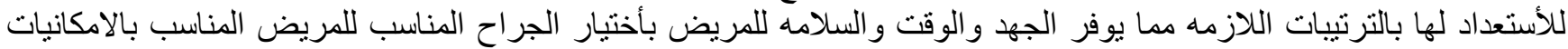

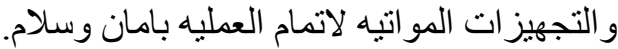

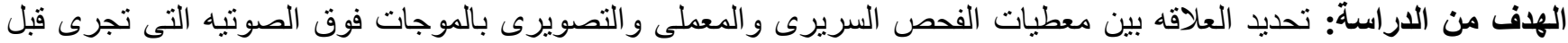

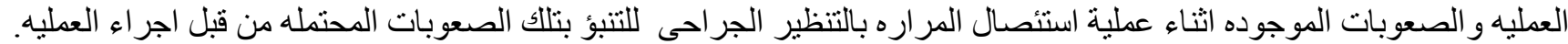

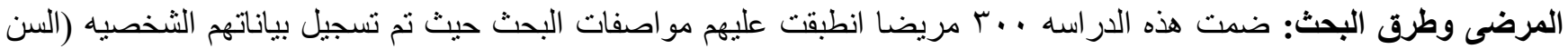

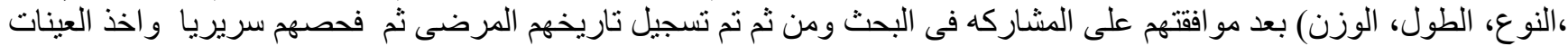

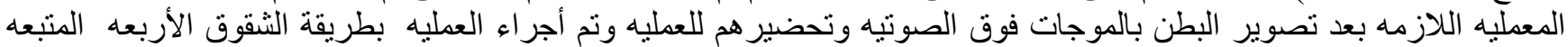

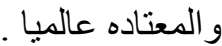

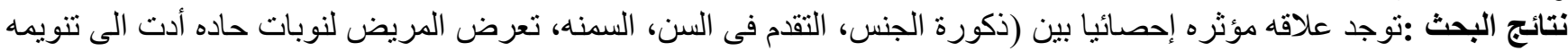

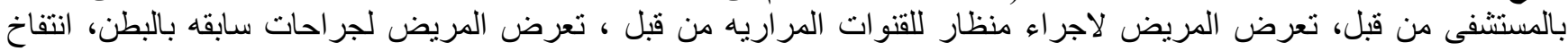

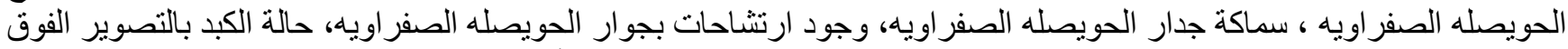

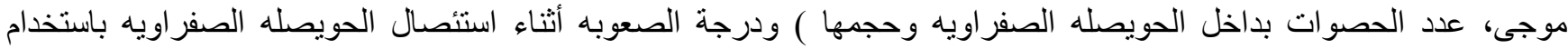
التنظير الجر احى. الاحس.

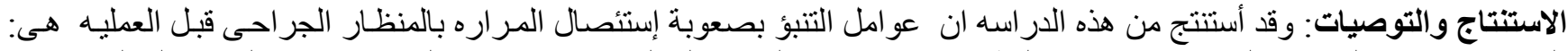

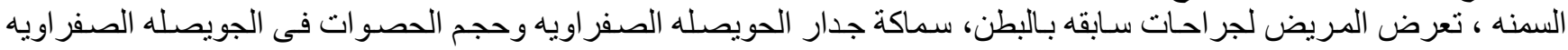

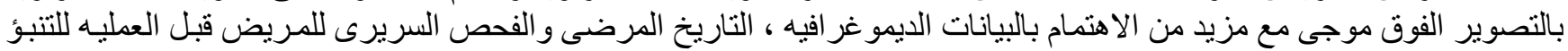

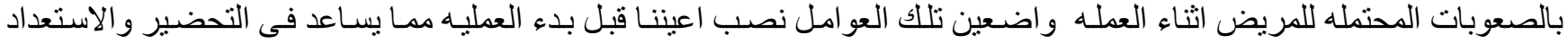

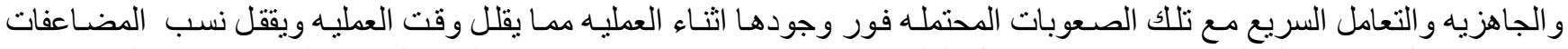

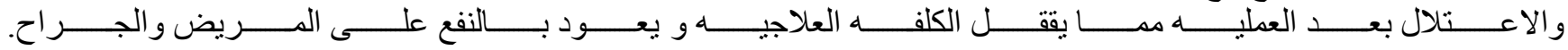

